\title{
Soil moisture active and passive microwave products: intercomparison and evaluation over a Sahelian site
}

\author{
C. Gruhier ${ }^{1}$, P. de Rosnay ${ }^{2}$, S. Hasenauer ${ }^{3}$, T. Holmes ${ }^{4}$, R. de Jeu ${ }^{5}$, Y. Kerr ${ }^{1}$, E. Mougin ${ }^{1}$, E. Njoku ${ }^{6}$, F. Timouk ${ }^{1}$, \\ W. Wagner ${ }^{3}$, and M. Zribi ${ }^{1}$ \\ ${ }^{1}$ Centre d'Études Spatiales de la BIOsphère, UMR 5126 (CNRS, CNES, IRD, UPS), Toulouse, France \\ ${ }^{2}$ European Centre for Medium-Range Weather Forecasts, Reading, UK \\ ${ }^{3}$ Institute of Photogrammetry and Remote Sensing, Vienna University of Technology, Vienna, Austria \\ ${ }^{4}$ USDA-ARS Hydrology and Remote Sensing Laboratory, Beltsville, USA \\ ${ }^{5}$ Faculty of Earth and Life Sciences, Vrije Universiteit, Amsterdam, The Netherlands \\ ${ }^{6}$ Jet Propulsion Laboratory, Pasadena, USA
}

Received: 3 August 2009 - Published in Hydrol. Earth Syst. Sci. Discuss.: 5 August 2009

Revised: 18 December 2009 - Accepted: 23 December 2009 - Published: 22 January 2010

\begin{abstract}
This paper presents a comparison and an evaluation of five soil moisture products based on satellite-based passive and active microwave measurements. Products are evaluated for 2005-2006 against ground measurements obtained from the soil moisture network deployed in Mali (Sahel) in the framework of the African Monsoon Multidisciplinary Analysis project. It is shown that the accuracy of the soil moisture products is sensitive to the retrieval approach as well as to the sensor type (active or passive) and to the signal frequency (from $5.6 \mathrm{GHz}$ to $18.8 \mathrm{GHz}$ ). The spatial patterns of surface soil moisture are compared between the different products at meso-scale $\left(14.5^{\circ} \mathrm{N}-17.5^{\circ} \mathrm{N}\right.$ and $\left.2^{\circ} \mathrm{W}-1^{\circ} \mathrm{W}\right)$. A general good consistency between the different satellite soil moisture products is shown in terms of meso-scale spatial distribution, in particular after convective rainfall occurrences. Comparison to ground measurement shows that although soil moisture products obtained from satellite generally over-estimate soil moisture values during the dry season, most of them capture soil moisture temporal variations in good agreement with ground station measurements.
\end{abstract}

\section{Introduction}

Surface soil moisture is a key variable which controls the water and energy exchanges at the soil-vegetation-atmosphere interface. Koster et al. (2004) showed that the soil moisture feedback with precipitation is very strong in the three regions

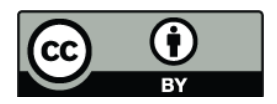

Correspondence to: C. Gruhier (claire.gruhier@cesbio.cnes.fr) of the US Great Plains, Asia and West Africa. In particular, in the Sahelian region of West Africa, Taylor et al. (2007) and Taylor (2008) showed that soil moisture and land surface processes influence meso-scale convective systems dynamics.

Quantitative soil moisture assessment is crucial for land surface modelling and understanding as well as for numerical weather prediction purpose. However, due to its high temporal and spatial variability, it is difficult to provide accurate quantitative information on soil moisture at regional and global scales. Several coordinated land surface modelling activities have provided insight into quantitative soil moisture characterisation at regional and global scale (Dirmeyer et al., 2006; Boone et al., 2009). Satellite remote sensing approaches also open the possibility to provide spatially integrated information on soil moisture over large areas. Microwave remote sensing at low frequencies is the most efficient approach to characterise soil moisture from space, with low atmospheric contribution (Njoku and Entekhabi, 1996; Jones et al., 2004; Wagner et al., 2007; Kerr, 2007).

Various active and passive microwave sensors have been measuring Earth emissions and reflection for several years. The Advanced Microwave Scanning Radiometer on Earth Observing System (AMSR-E) on the AQUA satellite is a passive microwave sensor. It has been providing brightness temperature at five frequencies from 6.9 to $89 \mathrm{GHz}$ since 2002 . AMSR-E C-band $(6.9 \mathrm{GHz})$ and X-band $(10.7 \mathrm{GHz})$ channels are suitable for soil moisture remote sensing (Njoku et al., 2003). On the Tropical Rainfall Measuring Mission (TRMM) satellite, the TRMM Microwave Imager (TMI) has been measuring microwave emission at five frequencies from $10.7 \mathrm{GHz}$ to $85.5 \mathrm{GHz}$ since 1997 . The wind scatterometer on the European Remote Sensing (ERS) satellites have

Published by Copernicus Publications on behalf of the European Geosciences Union. 
been performing continuous active microwave measurements at C-band (5.3 GHz) for 1991-1996 (ERS-1) and since 1996 (ERS-2) (European Space Agency, 1997). Their continuity has been ensured since 2006 by the Advanced Scatterometer (ASCAT) on the Meteorological Operational satellite (METOP). METOP/ASCAT has been providing near realtime soil moisture products since 2008. The ERS/SCAT and METOP/ASCAT series provides the longest consistent and continuous global scale soil moisture data set since 1992.

SMOS (Soil Moisture and Ocean Salinity) satellite of the European Space Agency (ESA), launched on 2 November 2009, is the first satellite devoted to soil moisture remote sensing. SMOS measurements use an L-band interferometer which has been shown to be optimal to capture soil moisture information from space (Kerr et al., 2001). From 2014 it should be followed by the Soil Moisture Active and Passive (SMAP) satellite of NASA which, by combining active and passive approaches, will provide soil moisture products at high resolution (http://smap.jpl.nasa.gov/).

Soil moisture retrieval is based on the relationship between soil moisture and soil dielectric constant which influences brightness temperatures and scatterometer coefficient from passive and active microwaves sensors, respectively. The sensitivity to soil water content might also be affected by Radio Frequency Interference (RFI) and vegetation optical depth, which are both accounted for in the retrieval algorithms. Although these soil moisture products are provided at relatively coarse resolutions, disaggregation approaches have been investigated in the past few years (Merlin et al., 2008). They proved to be highly relevant to provide soil moisture information at kilometer scale.

An important issue in remote sensing approaches concerns products validation. Several papers investigated soil moisture products evaluation (Dirmeyer et al., 2004; Pellarin et al., 2006; Wagner et al., 2007; Draper et al., 2009; Rüdiger et al., 2009). Draper et al. (2009) provided a comparison of four soil moisture products all based on AMSRE sensor over a temperate climate in Australia during 2006. Rüdiger et al. (2009), showed a comparison of three products (and one simulation) over the mainland of France from 2003 to 2005 , in addition to a ground measurements comparison. Gruhier et al. (2008) provided an evaluation of the AMSR-E soil moisture products of Njoku (2004) over the Gourma region of Sahel and the south-west of France for 2005. None of these studies consider a study area with same seasonal cycle for vegetation and soil moisture as it is the case over Sahel. This high temporal correlation between soil moisture and vegetation dynamics is however crucial for soil moisture retrieval accuracy and it might impact differently passive and active microwaves performances. Good knowledge of soil moisture product accuracy is particularly relevant to address over Sahel, which is a big area in terms of the strenght of the coupling between soil moisture and atmosphere.
In this paper five soil moisture products, obtained from current active and passive microwave sensors, are intercompared and evaluated over the Gourma region in Mali for 2005-2006. The study is based on ground measurements acquired in the framework of the AMMA (African Monsoon Multidisciplinary Analysis) program (Redelsperger et al., 2006; de Rosnay et al., 2009b), within the AMMACATCH observatory (Lebel et al. (2009); Mougin et al. (2009),AMMA-CATCH website link: http://ltheln21.hmg. inpg.fr/catch/?\&lang=en). This region is particularly relevant for satellite products validation. Since it is composed of uniform pattern of soil and vegetation, and its relatively limited vegetation cover is suitable for soil moisture remote sensing activities (Mougin et al., 2009). Two satellite products are derived from the AMSR-E measurements. They are provided by the National Snow and Ice Data Center (NSIDC) (Njoku, 2004) and by the VU University Amsterdam (VUA) in collaboration with NASA (Owe et al., 2008). The lastones also provide a product based on TRMM/TMI X-band data set. Two products are derived from the ERS scatterometer by Zribi and Decharme (2009) and by the Vienna University of Technology (Wagner et al., 2003).

The next section provides a short description of the test sites and ground measurements and presents the satellite data, followed by treatments applied and methodologies used. In Sect. 3, product intercomparison presents the importance of retrieval approaches, and soil moisture maps from the five products show the difference of sensitivity between passive and active microwave sensors. Comparison to ground measurements with statistical evaluation of product quality are provided. Section 4 concludes.

\section{Data and methods}

\subsection{Study region and ground data}

The AMMA international research program aims at providing a better understanding of West African monsoon and its physical processes. Three representative meso-scale sites have been instrumented along a North-South climatic gradient in West Africa (Redelsperger et al., 2006). They are located in Mali (North and Central Sahel), in Niger (SouthSahel) and in Benin (Soudanian site).

This study focuses on the Mali meso-scale site which is located in the Gourma region (Fig. 1a). The site spans 3 degrees in latitude from $14.5^{\circ} \mathrm{N}$ to $17.5^{\circ} \mathrm{N}$ and covers 1 degree in longitude from $2^{\circ} \mathrm{W}$ to $1^{\circ} \mathrm{W}$. It is characterised by Sahelian meteorological conditions with a short rainy season from end of June to September, followed by a long dry season from October until June. Mean annual rainfall is $370 \mathrm{~mm}$ per year, modulated by a strong inter-annual variability of the West African Monsoon (Frappart et al., 2009). Fig. 1b is a MrSID Landsat mosaic (R:Band 7, G:Band 4, B:Band 2). Over the considered area, the landscape is characterised by 
$65 \%$ of homogeneous gently undulating sandy dunes covered by annual herbaceous savanna (green area), 30\% of flat rocky-loam plain (pink area) and 5\% of clay-forested areas (very dark red on the Fig. 1b). This low vegetation cover of the study area is optimal for soil moisture remote sensing because of the low impact of the vegetation optical depth on the signal. The site has been instrumented with soil moisture and meteorological station networks, water and $\mathrm{CO}_{2}$ flux stations, LAI measurements as well as manual measurements of soil and vegetation properties (Mougin et al., 2009). As pointed out by Mougin et al. (2009), the relative homogeneity of the Gourma meso-scale site is particularly suitable for remote sensing evaluation of land surface products. Several studies investigated the validation and evaluation of satellite products, including soil moisture, vegetation parameters, and albedo (Baup et al., 2007; Zribi and Decharme, 2009; Gruhier et al., 2008; Samain et al., 2008; Mougin et al., 2009; de Rosnay et al., 2009a).

The soil moisture network is described in detail in de Rosnay et al. (2009b). It will be a validation area for the future SMOS products. For the considered period 2005-2006 the Gourma site includes ten stations. Each of them is instrumented with capacitive soil moisture sensors. Stations perform a continuous monitoring ( $15 \mathrm{~min}$ time step) of soil moisture profiles, including soil moisture at $5 \mathrm{~cm}$ depth.

Among the soil moisture network, three stations are considered because of the representativity of the latitudinal gradient (Table 1). They are located in In Zaket (ZAK), Ekia (EKI) and Agoufou (AGT) (Fig. 1c) and are all installed on coarse textured dune systems which are representative of the main land type of the region. The ZAK and EKI stations are located at intermediate topography levels (middle of hillslope), while the AGT station is located on top of a hillslope. As shown by de Rosnay et al. (2009b) the location of the station on the hillslope influences the volumetric soil moisture value. Stations located top (bottom) of hillslope tend to under-estimate (over-estimate) soil moisture values at larger scale. However, these authors showed that on coarse textured soil types, the soil moisture temporal dynamics are very fast and well captured independently of the location of the station on the slope. AGT has been shown to be the most representative station in terms of soil moisture variability, at both the kilometre scale and the super site scale $(50 \mathrm{~km} \times 50 \mathrm{~km})$. De Rosnay et al. (2009b) also showed that local scale ground measurements of soil moisture can be upscaled at a kilometre scale using a simple linear regression, with very good inter-annual and meso-scale stabilities. To correct local biases of the stations and to ensure spatial scale consistency between satellite and ground based soil moisture, local ground measurements used hereafter are up-scaled according to de Rosnay et al. (2009b).
Table 1. Soil moisture ground stations used for satellite products validation.

\begin{tabular}{llrc}
\hline Name & Short name & Latitude & Longitude \\
\hline In Zaket & ZAK & $16.572^{\circ} \mathrm{N}$ & $1.789^{\circ} \mathrm{W}$ \\
Ekia & EKI & $15.965^{\circ} \mathrm{N}$ & $1.253^{\circ} \mathrm{W}$ \\
Agoufou top & AGT & $15.345^{\circ} \mathrm{N}$ & $1.479^{\circ} \mathrm{W}$ \\
\hline
\end{tabular}

\subsection{Satellite data}

Five soil moisture products are evaluated in this study. Three products are derived from the AMSR-E and the TMI passive microwave sensors. Two products are derived from the ERS scatterometer sensor. The following next three subsections and Table 2 show basic information about these sensors and products.

According to the different satellite orbits and to the different inversion methods, data set sizes and amount of soil moisture values vary with products (Fig. 2). ERS/TUW and ERS/CETP (Centre d'Études Terrestres et Planétaires) products have significantly less available data than the three passive microwave data sets. There are three reasons for this: (i) the revisit and swath widths are different, (ii) the availability of ERS data is rather limited for the years 2005 and 2006 being beyond ERS life time, and (iii) inversion approaches used to obtain the two ERS/TUW and ERS/CETP products use several thresholds that filter out extreme values which reduce the size of the data sets for these two products. Among passive microwave data sets, AMSR-E/NSIDC is shown to contain twice more data than VUA products (AMSR-E/VUA and TMI/VUA) for which night pass are used and a filtering approach also reduces the data set in case of noise or extreme values.

A main issue in using passive microwaves is that the effects of soil moisture and vegetation water content on microwave emission are contrasting: a decrease in vegetation water content and an increase of soil moisture have the same effect on the signal, and conversely. Another issue concerns the strong temperature effects on day-time measurements (ascending orbit). A strong gradient in the top soil layers makes it difficult for soil moisture inversion in these conditions. To alleviate this problem only descending passes (i.e. night-time) are used in this study. Because of the lack of equivalent product in term of availability of data, only the night pass of the AMSR-E/NSIDC is used in this study (AMSR-E/NSIDC-used in the Fig. 2).

Satellite products used in this study are acquired at different time of the day (Table 2). So in order to inter-compare these products to each other a daily time scale is considered in this study. Accordingly, ground reference is used as daily mean soil moisture. Further investigations to study the diurnal variations of soil moisture in the different seasons and relate it to the time of acquisition of each sensor is an important topic which is kept for a future study. 


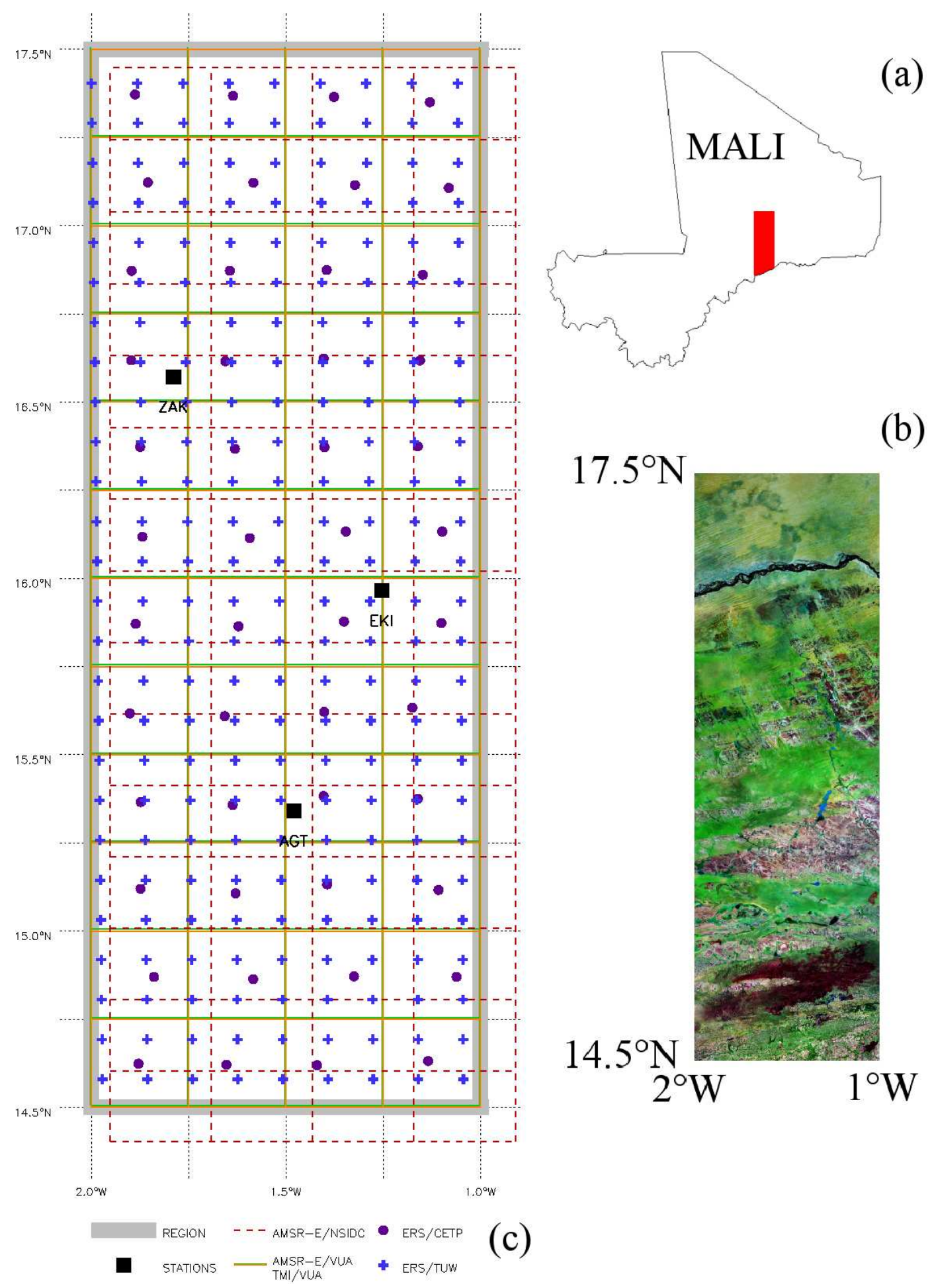

Fig. 1. (a) Localisation of study area inside Mali. (b) Land cover map from Landsat mosaic, green area are homogeneous gently undulating sandy dunes covered by annual herbaceous savanna (65\%), pink is flat rocky-loam plain (30\%), and very dark red is clay-forested areas (5\%). (c) Stations location (black squares) over the Gourma-Mali meso-scale site (grey box) and satellite soil moisture products grids. Regular grids are represented by red and green boxes for AMSR-E/NSIDC and AMSR-E/VUA-TMI/VUA respectively. For irregular grids central points of the pixels are indicated by purple and blue crosses for ERS/CETP and ERS/TUW respectively. 
Table 2. Radiometric characteristics and spatio-temporal resolutions of each soil moisture product.

\begin{tabular}{lllllll}
\hline Name & Type & $\begin{array}{l}\text { Frequencies } \\
\text { used }\end{array}$ & $\begin{array}{l}\text { Polarization } \\
\text { used }\end{array}$ & $\begin{array}{l}\text { Temporal } \\
\text { frequency }\end{array}$ & $\begin{array}{l}\text { Acquisition } \\
\text { time }\end{array}$ & $\begin{array}{l}\text { Spatial } \\
\text { resolution* }\end{array}$ \\
\hline AMSR-E/NSIDC & Passive & 10.7 & H and V & Daily & $01: 30$ & $25 \mathrm{~km}$ \\
AMSR-E/VUA & Passive & 6.9 & H and V & Daily & $01: 30$ & $25 \mathrm{~km}$ \\
ERS/CETP & Active & 5.3 & VV & 3 days & $10: 30$ & $25 \mathrm{~km}$ \\
ERS/TUW & Active & 5.3 & VV & 3 days & $10: 30$ & $12.5 \mathrm{~km}$ \\
TMI/VUA & Passive & 10.7 & H and V & Daily & various & $25 \mathrm{~km}$ \\
\hline
\end{tabular}

*The spatial resolution is that of the product.

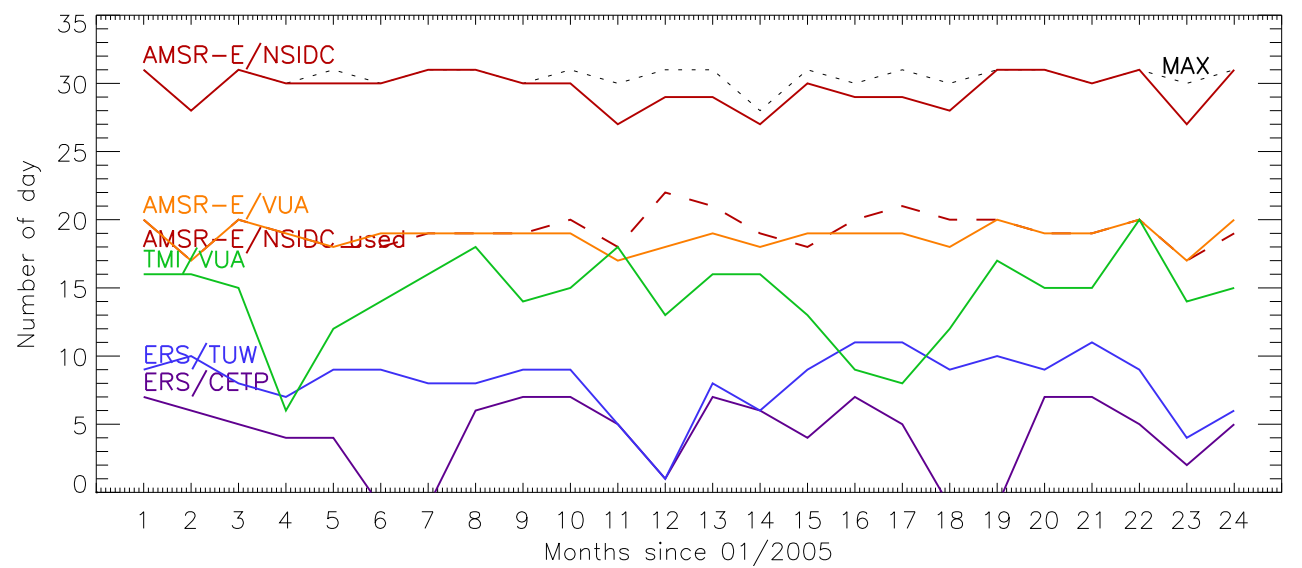

Fig. 2. Temporal coverage for each soil moisture product, in day by month over the Gourma window (counted when at least one pixel is available). The five soil moisture products are represented by color lines (ASMR-E/NSIDC, AMSR-E/VUA, TMI/VUA, ERS/CETP, ERS/TUW) and the red dotted line correspond to the data used from the ASMR-E/NSIDC product.

\subsubsection{AQUA AMSR-E satellite, sensor and products}

The passive microwave AMSR-E instrument was launched on the AQUA satellite in May 2002. AQUA crosses over the equator at a local solar time of 01:30 p.m./a.m. for ascending/descending orbit on a polar sun-synchronous orbit (14 orbits/day). AMSR-E records brightness temperature at frequencies of $6.9,10.7,18.7,23.8,36.5$ and $89 \mathrm{GHz}$, at horizontal $(\mathrm{H})$ and vertical $(\mathrm{V})$ polarisations. The mean spatial resolution at $6.9 \mathrm{GHz}$ is about $56 \mathrm{~km}$ with a swath width of $1445 \mathrm{~km}$.

AMSR-E/NSIDC products Level3 B02 are used in this study. They are provided at a $25 \mathrm{~km}$ regular grid and soil moisture is obtained from an iterative inversion algorithm using $10.7 \mathrm{GHz}$ and $18.7 \mathrm{GHz}$ data (Njoku et al., 2003). Initially, this algorithm was developed for $6.9 \mathrm{GHz}$ and 10.7 GHz frequencies. Due to RFI (Radio Frequency Interferences) affecting $\mathrm{C}$-band data over large regions, the 10.7 GHz and 18.7 GHz data were used instead. Land surface parameters like soil moisture, vegetation water content, and surface temperature are also provided as AMSR-E products.

An independent product (AMSR-E/VUA) is evaluated in this paper. It has been developed by the VU University Amsterdam in collaboration with NASA (Owe et al., 2008). It is obtained by applying the three parameter Land Parameter Retrieval Model (LPRM, v03d) to the dual polarized $6.9 \mathrm{GHz}$ channels to retrieve soil moisture and vegetation water content simultaneously without using any additional information on vegetation cover. In order to ensure a good accuracy of the products, only data of descending orbits, for which temperature gradient in the emitting layer are low, are used in this algorithm.

\subsubsection{ERS-Scatterometer satellite, sensor and products}

ERS-1 was launched in July 1991 and ERS-2 April 1995, both with a scatterometer on board. The first objective of this sensor is to measure wind over oceans, but its measurements have been shown to be highly suitable for soil moisture remote sensing (Magagi and Kerr, 1997; Wagner et al., 1999). ERS-2 is on a sun-synchronous polar orbit, completing in $100 \mathrm{~min}$ ( 14 orbits/day), with equator crossing times at 10:30/22:30 (descending/ascending). The scatterometer records the backscattering coefficient at $5.3 \mathrm{GHz}$ at $\mathrm{VV}$ polarisation at spatial resolution of $47 \mathrm{~km}$ for two angles.

The ERS/TUW product consists of soil moisture indexes provided at a $12.5 \mathrm{~km}$ spatial sampling by interpolation. The retrieval algorithm computes soil wetness indexes using wet 
and dry difference normalisation from descending and ascending orbits which makes it suitable at global scale. Minimum and maximum values of the backscatter signal observed during 1992-2007 period are used to define the range of variations. Soil moisture indexes are in the range of 0 to $100 \%$, which correspond to residual water content and saturation respectively. In this study, local values of saturation are used to convert relative soil moisture index values to soil moisture volumetric values (given in $\mathrm{m}^{3} / \mathrm{m}^{3}$ ). According to observed soil moisture at the Agoufou station, saturated and residual soil moisture are set to $23 \% \mathrm{~m}^{3} / \mathrm{m}^{3}$ and $0 \% \mathrm{~m}^{3} / \mathrm{m}^{3}$, respectively. These volumetric soil moisture values were only determined from sandy soils, which is the main soil type.

A further ERS soil moisture product considered in the present paper is provided by Zribi and Decharme (2009) with a $25 \mathrm{~km}$ spatial sampling. This product, hereafter referred as ERS/CETP (Centre d'Études Terrestres et Planétaires) has been specifically developed for the West African region in the context of the AMMA project, so in contrast to the ERS/TUW product it is not available at global scale. A statistical inversion has been applied on the signal based on local calibrations over the AMMA sites. The backscatter coefficients are normalized to $40^{\circ}$ on each cell to decrease angular variation effects. Providers of this soil moisture product eliminate the roughness effects as well as vegetation influence using NDVI from AVHRR measurements. Only the descending pass are provided for this study. For this product, soil moisture is provided in volumetric units.

\subsubsection{TRMM-TMI satellite, sensor and product}

The TMI sensor on board TRMM, launched in November 1998, is a passive microwave instrument. It is designed for tropical rainfall observations with a circular orbit and an inclination of 35 degrees to the Equator. Each orbit is completed in $91 \mathrm{~min}$ (16 orbits/day) with a swath around $400 \mathrm{~km}$. The TMI instrument operates at frequencies of 10.7, 19.4, $21.3,37$ and $85.5 \mathrm{GHz}$ in horizontal and vertical polarisations ( $21.3 \mathrm{GHz}$ band only in $\mathrm{H})$. The mean spatial resolution varies from $50 \mathrm{~km}$ at $10.7 \mathrm{GHz}$ to $6 \mathrm{~km}$ at $85.5 \mathrm{GHz}$.

The volumetric soil moisture product provided by the TMI/VUA is retrieved from the $10.7 \mathrm{GHz}$ measurements, with the same retrieval model as the AMSR-E/VUA product (LPRM v03, Owe et al., 2008). Only the night data are used for this study (between 07:00 p.m. and 08:00 a.m.), and these are provided on a 0.25 degree regular grid.

\subsection{Methods}

In order to validate the satellite products, ground measurements of soil moisture are spatially up-scaled as indicated in Sect. 2.1. Satellite products used in this study are acquired at different time of the day (Table 2). So in order to intercompare these products to each other a daily time scale is considered in this study. Accordingly, ground reference is used as daily mean soil moisture. Further investigations to study the diurnal variations of soil moisture in the different seasons and relate it to the time of acquisition of each sensor is an important topic which is kept for a future study.

For the purpose of satellite products intercomparison, all products are resampled to a reference grid with the nearest neighbour method. This ensures keeping the intercomparison as fair as possible without performing any interpolation on the products that would influence the results. The grid of the ERS/TUW soil moisture product is used here as reference because it has the finest resolution (Table 2). Statistics are computed for each pair of products when a minimum of 33 pixels are available for the two considered products at the same date. This threshold ensures having enough data for the comparison and it enables to compute statistics between the products.

Mean Relative Difference (MRD) is traditionally used to determine the most representative station inside a soil moisture network (Vachaud et al., 1985). In this study, MRD is used to compare soil moisture values of each product to the mean value obtained from the five products. For each SM product $i, \mathrm{MRD}_{i}$ is computed as:

$\operatorname{MRD}_{i}=\frac{1}{m} \sum_{j=1}^{m} \frac{S_{i, j}-\bar{S}_{j}}{\overline{S_{j}}}$

where $S_{i, j}$ is the soil moisture value of the considered product $i$ at Day Of the time Series (DOS) $j, \overline{S_{j}}$ is soil moisture value averaged over all products at DOS $j$, and $m$ is the amount of DOS for which soil moisture is available from all the five products. The $\mathrm{MRD}_{i}$ value indicates the position of the product $i$ relatively to the products-average. A MRD value of 0 indicates that the considered product is representative of the products average. A positive MRD indicates that this product over-estimates soil moisture compared to the products average, while a negative MRD indicates an underestimation. The stability of the MRD during the time series is provided by its standard deviation value. Lowest standard deviation value indicates strongest stability and best representativeness in terms of soil moisture temporal variability.

In addition to MRD, usual statistical coefficients are used in this study. Root Mean Squared Error (RMSE) is used to define the difference in volumetric soil moisture between satellite and ground measurements. Correlation coefficient, $R$, quantifies their temporal dynamics consistency.

Evaluation of remote sensing products against ground measurements is very difficult and it needs to be taken with great care. Ground stations provide extremely local estimates of soil moisture while satellite measurements, as well as land surface modelling approaches, give spatially integrated estimates of surface soil moisture. Surface soil moisture scaling properties mainly result from ground heterogeneities (land cover, soil properties, topography) and precipitation heterogeneities. De Rosnay et al. (2009b) have investigated surface soil moisture scaling properties over the Gourma meso-scale 
site. They have shown that scaling properties of surface soil moisture are stable at the meso-scale site.

Both volumetric and normalized soil moisture values are compared to ground measurements, in order to better understand and quantify agreement between satellite products and ground truth. Normalized values are obtained following:

$S_{j n}=\frac{S_{j}-\bar{S}}{\sigma}$

where $S_{j n}$ is is the soil moisture value of the considered DOS $j, \bar{S}$ is soil moisture value averaged over all DOS, and $\sigma$ is the standard deviation of series $S$.

\section{Results}

\subsection{General features of surface soil moisture products}

Figure 3 gives general information on surface soil moisture range (minimum and maximum values) and indicates soil moisture variability (standard deviation). Theses values are obtained for 2005-2006 for each soil moisture product (AMSR-E/NSIDC, AMSR-E/VUA, ERS/CETP, ERS/TUW, TMI/VUA), as well as for local ground measurements after up-scaling fonction is applied (ZAK, EKI, AGT). Several spatial scales are considered: (i) at the pixel scale, for which ground measurements and satellite products are available (ZAK, EKI, AGT) and (ii) averaged at meso-scale for the satellite products only.

Results of Fig. 3 show substantial differences between the different soil moisture products in terms of soil moisture range and soil moisture temporal variability. Ground measurements indicate very low values of soil moisture during the dry season (minimum close to $0 \% \mathrm{~m}^{3} / \mathrm{m}^{3}$ ), which are consistent among the three stations. These low values are representative of lowest soil moisture values encountered for coarse textured soils in this region (de Rosnay et al., 2009b). Apart AMSR-E/NSIDC, all products reach low minimum values of soil moisture during the dry season at both the pixel and the meso-scales (between 0\% and 1.6\%). Lowest soil moisture values from the AMSR-E/NSIDC product are in the range of $4 \%$ to $5.6 \%$ at the pixel scale and $2.4 \%$ at the mesoscale. The difficulty to provide low soil moisture values is specific to the AMSR-E/NSIDC product, as already shown by previous study over this area or in the context of other climatic conditions (Gruhier et al., 2008; Rüdiger et al., 2009; Draper et al., 2009).

Maximal soil moisture values recorded by the stations are $13.39 \%, 27.26 \%$, and $22.62 \% \mathrm{~m}^{3} / \mathrm{m}^{3}$, for ZAK, EKI, and AGT, respectively. The ZAK station, located north of the climatic gradient, represents the lowest range of soil moisture variations and the driest conditions. Over the ZAK pixel, all soil moisture products overestimate soil moisture values in wet conditions compared to the ground station. For the AGT pixel, TMI/VUA soil moisture maximum value is very close to those of the ground station, while ERS/CETP and

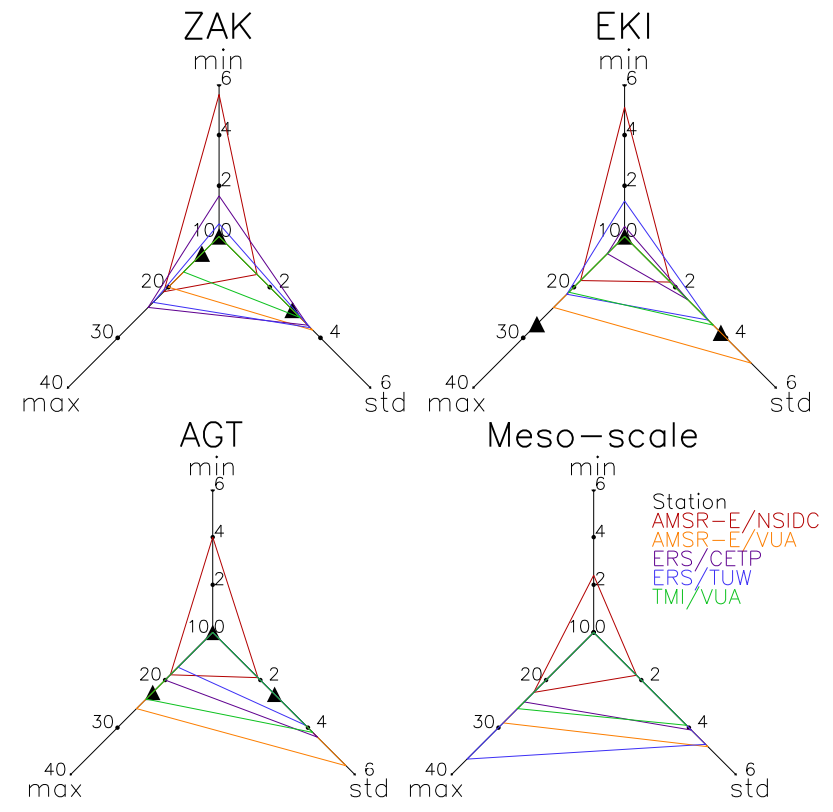

Fig. 3. Volumetric Soil Moisture (in $\% \mathrm{~m}^{3} / \mathrm{m}^{3}$ ) from satellite products and ground measurements at the ZAK, EKI and AGT stations and averaged at the meso-scale. Minimum and maximum value and standard deviation are calculated for the time series 2005-2006. Minimal and maximal values for ERS/TUW are from converted original indexes values as indicated in Sect. 2.3.

AMSR-E/VUA, AMSR-E/NSIDC and ERS/TUW maximal values are underestimated. Figure 3 shows that standard deviation of ground soil moisture time series lies in the range of $2.9 \%$ to $3.8 \%$ for the three stations. For the AMSR-E/NSIDC product, standard deviation varies in the range of $1.5 \%$ to $1.9 \%$ over the three pixels and its value is $1.8 \%$ at mesoscale. Comparison with ground stations at the pixel scale clearly shows that AMSR-E/NSIDC underestimates the soil moisture variability. In opposite AMSR-E/VUA, ERS/CETP, ERS/TUW, TMI/VUA overestimate the soil moisture variability over the ZAK et AGT station, while only AMSRE/VUA overestimates for the EKI pixel.

At the meso-scale, the ERS/TUW product shows a maximal value of $36.6 \% \mathrm{~m}^{3} / \mathrm{m}^{3}$ which is incompatible with the saturation value used to convert soil moisture index values to volumetric values. This can be explained by some index values higher than 100 in this product. Indeed, the maximal index value reached by ERS/TUW product is 159 . The count of value higher than 100.0 represents $0.77 \%$ of valid data.

The MRD method, described in Sect. 2.3, is applied here for the soil moisture satellite products as shown in Fig. 4. MRD values are very low, showing that for long time series mean soil moisture values provided by the different satellites and sensors are very close from one another. It can be explained by compensations between over-estimation and under-estimation periods. It is interesting to notice that the two AMSR-E products have the largest and lowest MRD, corresponding to highest and lowest mean soil moisture 


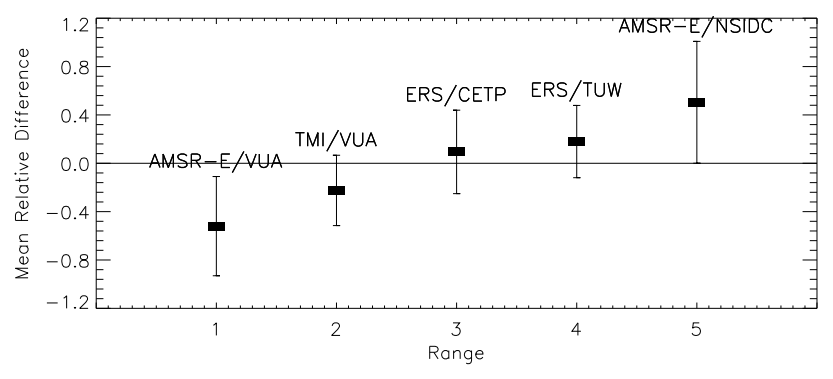

Fig. 4. Mean relative difference (MRD) value for each satellite product. Negative values of MRD indicate that the product underestimates soil moisture compared to the products average, while positive values indicate an over-estimation.

values, respectively. Both products also show largest standard deviations which indicates that this position compared to the products average is not constant during the time series. TMI/VUA, ERS/TUW and particularly ERS/CETP products are the nearest of the product average (low values of MRD).

Among the five soil moisture products evaluated here, some are based on the same remote sensing data set and others use the same retrieval approach. Figure 5 shows the three possible comparisons of pairs of products: 1) both products based on AMSR-E sensor (Fig. 5a), 2) both products based on scatterometer sensor (Fig. 5b), 3) both products based on same retrieval approach from LPRM model by VUA (Fig. 5c). Soil moisture values used in these scatterplots are from the three pixels corresponding to the stations.

AMSR-E/NSIDC and AMSR-E/VUA products, both based on AMSR-E data set, have a correlation ratio of 0.732 . This result indicates a strong correlation according to the sample of 1340 data. However, the two products are not in agreement for dry soil moisture conditions (Fig. 5a). Indeed, AMSR-E/NSIDC product do not provide soil moisture values lower than $5 \% \mathrm{~m}^{3} / \mathrm{m}^{3}$. This product shows a lack of dynamics, particularly in low values as already shown by previous studies (Gruhier et al., 2008; Rüdiger et al., 2009; Draper et al., 2009). This leads to Root Mean Square Error (RMSE) values to be relatively high (5.79) between the AMSR-E/NSIDC and the AMSR-E/VUA products.

In contrast, the Fig. $5 \mathrm{~b}$ shows that the two products based on scatterometer data provide soil moisture values in great agreement with a correlation ratio of 0.776 and a RMSE of $2.34 \% \mathrm{~m}^{3} / \mathrm{m}^{3}$.

A comparison between the AMSR-E/VUA and TMI/VUA products is shown in Fig. 5c. These products are obtained from different sensors but they are based on the same inversion algorithm. They are in very good agreement with a correlation ratio of 0.82 and a RMSE of $3.21 \% \mathrm{~m}^{3} / \mathrm{m}^{3}$.

This result clearly shows that the retrieval approach and the sensor characteristics are both of high importance for the final soil moisture product characteristics. Using a remote sensing frequency sensitive to soil moisture is necessary but not sufficient to access accurately soil moisture information. The retrieval algorithm also plays a crucial role in the accuracy of the retrieved soil moisture, as shown by the comparison between AMSR-E/NSIDC, AMSR-E/VUA and TMI/VUA.

\subsection{Meso-scale surface soil moisture characteristics}

\subsubsection{Soil moisture maps}

Figure 6 shows soil moisture maps from the five satellite products over the meso-scale site. Fourteen days are selected because of their representativeness of all cases encountered during the two years considered in this study. Soil moisture maps available from the five products over the two years was studied. Specifics cases were identified, similar maps as well as cases of maps providing different results. For six of these days, at least one product is characterised by missing data for the entire meso-scale window. ERS/CETP and ERS/TUW products, both based on scatterometer data, are particularly affected by missing data (Fig. 2), due to the fact that they are obtained from regression approaches using masking criteria for extreme soil moisture values. For ERS/TUW product, extrem wet or dry soil conditions are not provided (e.g. DOS 229 and DOS 372, Fig. 6). This missing values can be explained by the beyond the limit soil moisture thresholds defined from past measurements. Missing values are also due to operations conflicts with other sensors.

During DOS 229, soil moisture values provided by ERS/TUW product in the south part of the meso-scale area are particularly high. Soil moisture values are higher than $24.83 \%$ which should not be possible as already introduced in Sect. 3.1.

DOS 213, 216, 229, and 614 show rather good agreement between the five soil moisture products. They all depict contrasted spatial distribution of soil moisture values at mesoscale. DOS 527 also indicates a relative good consistence between soil moisture maps for AMSR-E/NSIDC, AMSRE/VUA, and ERS/TUW products which clearly show a wet patch centred on $1.8^{\circ} \mathrm{W} / 15^{\circ} \mathrm{N}$. However, TMI/VUA product does not capture this wet patch on DOS 527 and indicates relatively uniform soil moisture conditions at meso-scale. That can be explained by different times of overpass between the satellites.

During DOS 197 and 566, ERS/CETP product underestimates soil moisture values in the south part of the area, compared to the four other products which are in good agreement.

DOS 372 and 477 (dry conditions) show that both ERS derived products, overestimate soil moisture values in the northern part of the area. This two DOS are representative of existing differences between active (ERS/CETP, ERS/TUW) and passive (AMSR-E/NSIDC, AMSR-E/VUA and TMI/VUA) products during dry season (not shown). The assumption to explain the over-estimation in the north part is that backscatter may be enhanced by volume scattering when the soil is completely dry (for example in desert areas). For this reason, providers of these soil moisture products 
Table 3. Mean values of spatial correlations shown in Fig. 7, for the entire 2005-2006 period (left), for 2005-2006 monsoon seasons (middle) and for 2005-2006 dry seasons (right).

\begin{tabular}{|c|c|c|c|c|c|c|c|c|c|c|c|c|}
\hline \multirow[b]{2}{*}{ PRODUCT } & \multicolumn{4}{|c|}{ Two years } & \multicolumn{4}{|c|}{ Monsoon seasons } & \multicolumn{4}{|c|}{ Dry seasons } \\
\hline & $\begin{array}{r}\text { AMSR-E } \\
\text { NSIDC }\end{array}$ & $\begin{array}{r}\text { AMSR-E } \\
\text { VUA }\end{array}$ & $\begin{array}{r}\text { ERS } \\
\text { CETP }\end{array}$ & $\begin{array}{r}\text { ERS } \\
\text { TUW }\end{array}$ & $\begin{array}{r}\text { AMSR-E } \\
\text { NSIDC }\end{array}$ & $\begin{array}{r}\text { AMSR-E } \\
\text { VUA }\end{array}$ & $\begin{array}{r}\text { ERS } \\
\text { CETP }\end{array}$ & $\begin{array}{r}\text { ERS } \\
\text { TUW }\end{array}$ & $\begin{array}{r}\text { AMSR-E } \\
\text { NSIDC }\end{array}$ & $\begin{array}{r}\text { AMSR-E } \\
\text { VUA }\end{array}$ & $\begin{array}{r}\text { ERS } \\
\text { CETP }\end{array}$ & $\begin{array}{l}\text { ERS } \\
\text { TUW }\end{array}$ \\
\hline TMI/VUA & 0.12 & 0.50 & 0.24 & 0.24 & 0.37 & 0.66 & 0.27 & 0.45 & 0.02 & 0.44 & 0.23 & 0.17 \\
\hline ERS/TUW & -0.07 & 0.40 & 0.61 & & 0.14 & 0.56 & 0.51 & & -0.17 & 0.32 & 0.65 & \\
\hline ERS/CETP & -0.16 & 0.39 & & & 0.07 & 0.21 & & & -0.26 & 0.48 & & \\
\hline AMSR-E/VUA & 0.11 & & & & 0.42 & & & & -0.01 & & & \\
\hline
\end{tabular}

(a) AMSR-E products

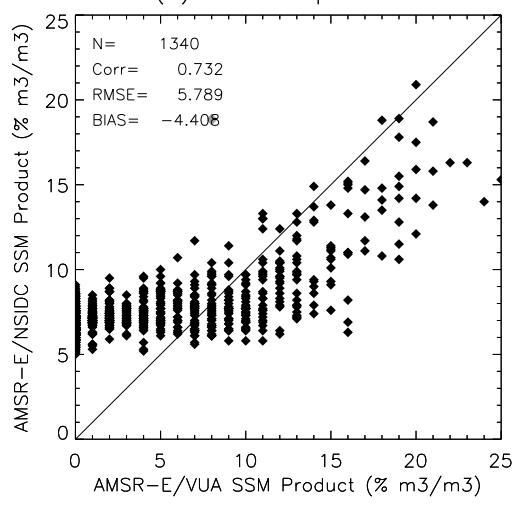

(b) Scatterometer products

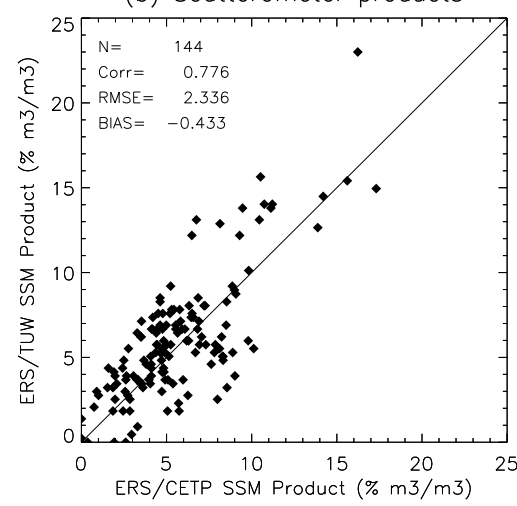

(c) Products from some method

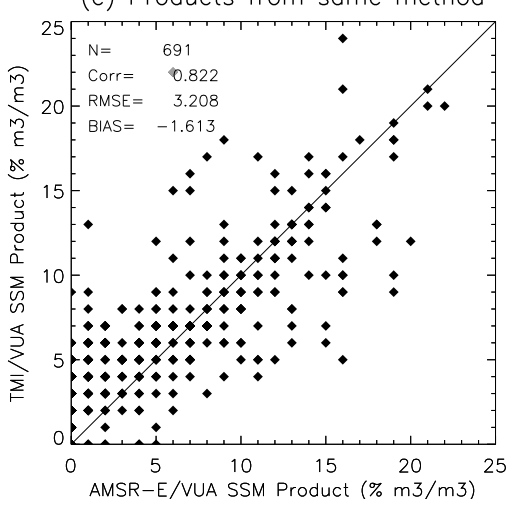

Fig. 5. Relation between different satellite soil moisture products for 2005-2006 on the three validation sites. Panel (a) shows the relation between the two AMSR-E products (AMSR-E/NSIDC and AMSR-E/VUA). Panel (b) shows the relation between the ERS products (ERS/TUW and ERS/CETP). Panel (c) shows the relation between the TMI/VUA and AMSR-E/VUA products obtained with different sensors.

recommend to mask this region. The same analysis was conducted over a smaller window limited to $14.5^{\circ} \mathrm{N}-16.75^{\circ} \mathrm{N}$ and $2^{\circ} \mathrm{W}-1^{\circ} \mathrm{W}$ in longitude (not shown). Excluding the northern part of the window does not influence the overall intercomparison results. Thus, the whole of the study area is used in this paper.

Spatial correlations are calculated between each soil moisture map when data are available for a minimum on 33 pixels for each pair of products in the studied Gourma-Mali window. Temporal evolutions of the obtained spatial correlation values are shown in Fig. 7 and summarised in Table 3 for different periods. In general a high correlation between the pairs of products is obtained during the monsoon season compared to the dry season. This is explained by the higher soil moisture gradient due to rain events during the wet saison. While during the dry season, the correlation ratio is more sensible to the low inadequancy between soil moisture maps. However, this is less marked when the ERS/CETP soil moisture product is in the pair. The high consistence between these soil moisture maps during all the period is due to the over-estimation in the north part by both products. Correlation between AMSR-E/NSIDC and AMSR-E/VUA presents the highest seasonal sensitivity, with variations between 0.96 during rainy seasons down to -0.75 during the 2005-2006 dry seasons (Fig. 7). This is confirmed by mean seasonal values (Table 3 ) which show mean correlation ratios of 0.422 during monsoon and -0.005 during dry season, respectively.

For the entire 2005-2006 period, spatial mean correlation between AMSR-E/NSIDC and AMSR-E/VUA is relatively low (0.113). The best agreement between products is obtained between ERS/CETP and ERS/TUW products (0.609), both obtained from the same sensor (ERS). Good agreement between the AMSR-E/VUA and TMI/VUA product (0.503) is also obtained. It is interesting to notice that although these last two products are not obtained from the same sensor and frequency (AMSR-E and TMI), they are obtained from the same retrieval approach (Owe et al., 2008).

\subsubsection{Time-Latitude representation of soil moisture}

Time-latitude diagrams are shown in Fig. 8 for the five soil moisture products for 2005-2006. They represent seasonal and latitudinal soil moisture variability for each product. Monsoon season in July-August-September is clearly distinguished with highest soil moisture values. Seasonal cycles of soil moisture are particularly contrasted for AMSR-E/VUA, ERS/TUW and TMI/VUA products. In contrast, amplitude is relatively small for AMSR-E/NSIDC 


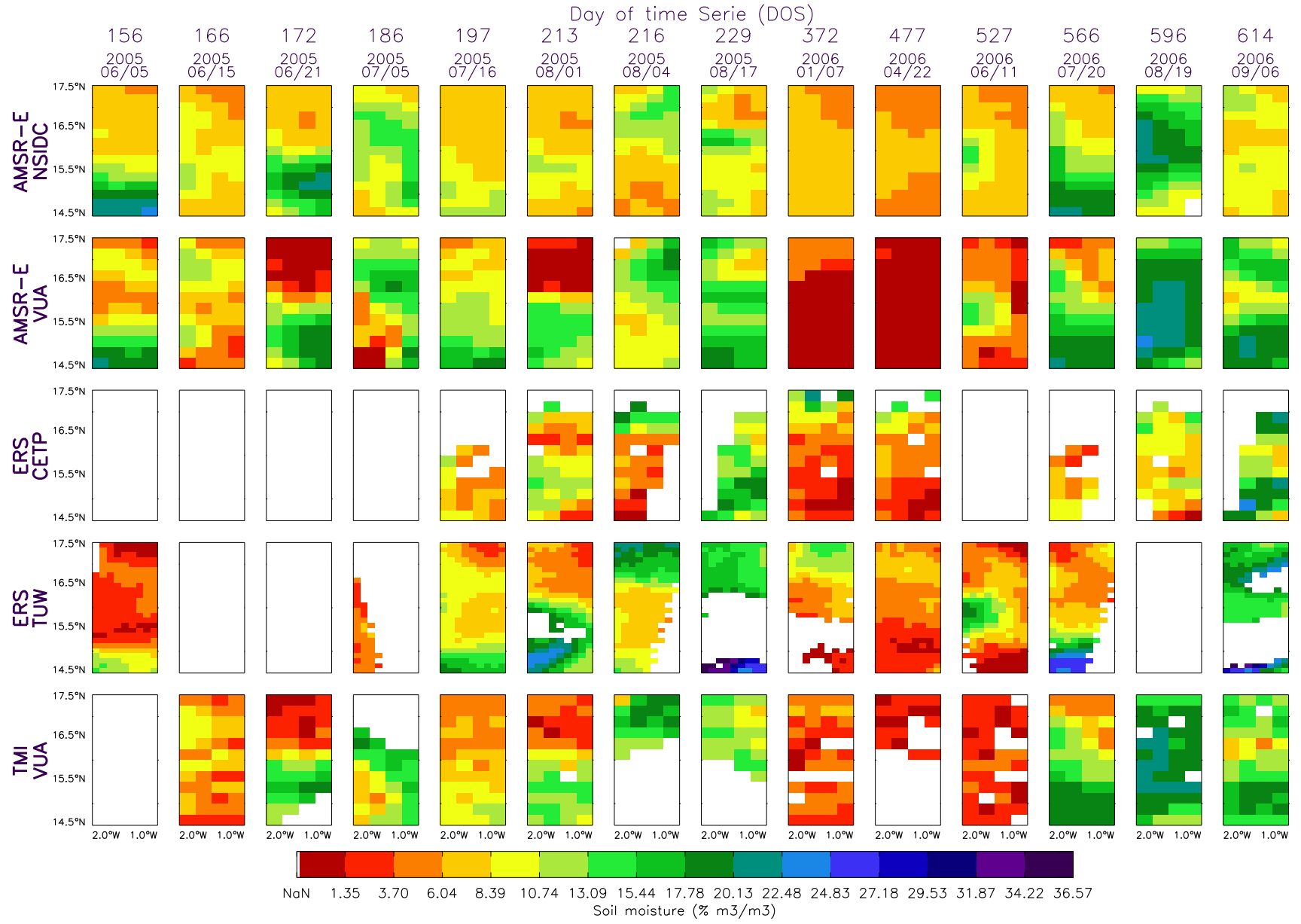

Fig. 6. Soil moisture maps over the Gourma-Mali window for the five products (AMSR-E/NSIDC, AMSR-E/VUA, ERS/CETP, ERS/TUW, TMI/VUA), for different Day of time Series (DOS 156, 166, 172, 186, 197, 213, 216, and 229 for 2005 and DOS 372, 477, 527, 566, 596, and 614 for 2006).

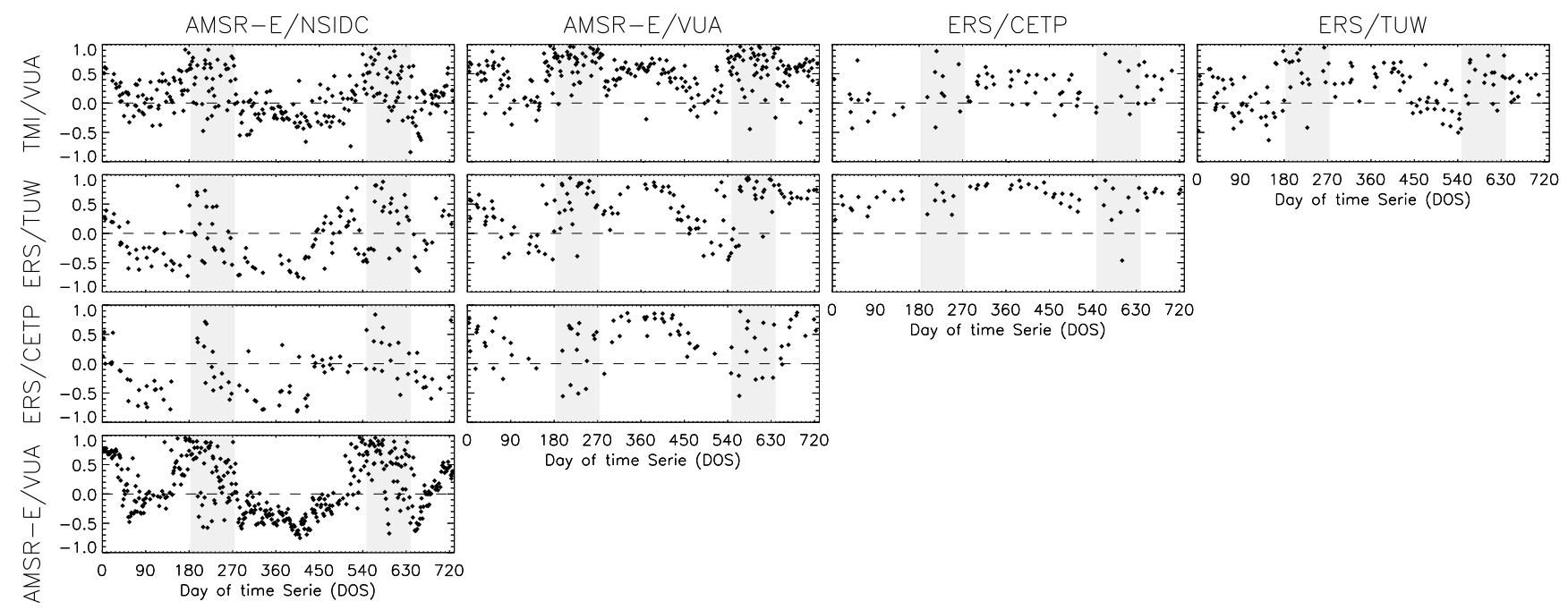

Fig. 7. Temporal evolution of spatial correlations between soil moisture products for the Gourma-Mali window. Background shaded grey areas indicate monsoon seasons. 


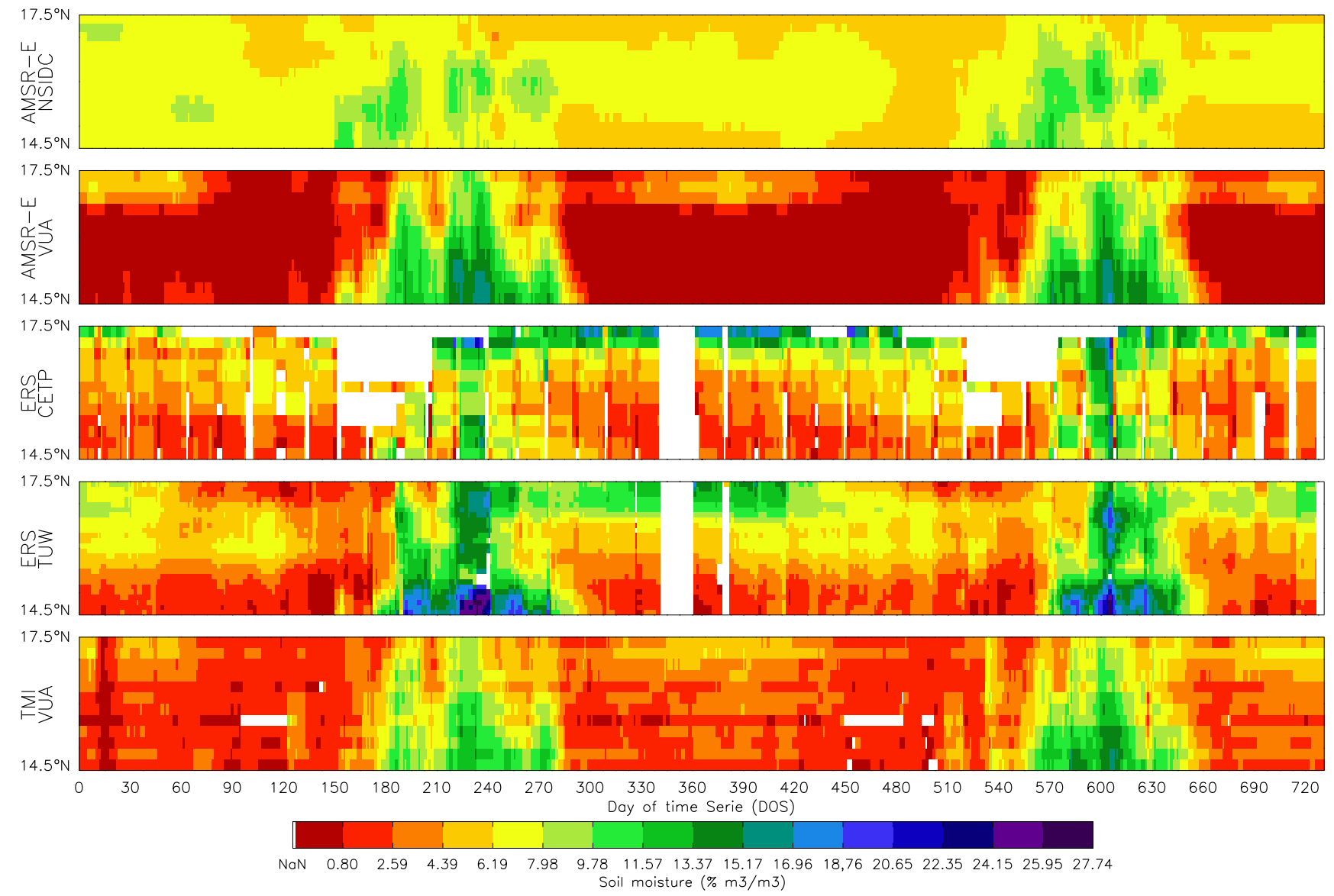

Fig. 8. Time-Latitude diagrams of the five soil moisture products (AMSR-E/NSIDC, AMSR-E/VUA, ERS/CETP, ERS/TUW, TMI/VUA) for 2005-2006, represents averaged longitude over the Gourma site [2W-1W]. For purpose of clarity a 10-day average moving window was applied in this figure.

and ERS/CETP products due to combined effects of overestimated soil moisture during dry seasons and underestimated soil moisture during the wet season. ERS/CETP and ERS/TUW, both based on ERS data set, indicate very high soil moisture values $\left(>8 \% \mathrm{~m}^{3} / \mathrm{m}^{3}\right)$ during the dry season over the north part of the study area, as mentioned in Sect. 3.2.1. For both products, the lowest soil moisture values are obtained just before the beginning of the wet season. Scatterometer coefficients obtained during the dry season are higher than values used like lowest reference, causing an over-estimation during the dry season.

Latitudinal soil moisture profiles are shown in Fig. 9 for January-February-March, April-May-June, July-AugustSeptember, and October-November-December for the five satellite products and the three ground stations. Ground stations clearly show a contrasted annual cycle, with soil moisture values ranging between 7\% during the wet season and less than $1 \%$ during the rest of the year. During April-MayJune, which is the end of the dry season and the very beginning of the monsoon season, a few precipitation events lead to a slight increase soil moisture values of AGT station in the south part of the area. The AMSR-E/VUA soil moisture product is in the best agreement with the ground measurements compared to other products, particularly during the dry periods. It is able to capture the season amplitude and to some extent the latitudinal profile. TMI/VUA also performs well in terms of soil moisture seasonal amplitude. AMSR-E/NSIDC in contrast underestimates soil moisture seasonal dynamics. ERS/CETP and ERS/TUW overestimate soil moisture values in the north part of the area. This is consistent with results shown in Fig. 6.

\subsection{Soil moisture comparison with ground measurements}

Figure 10 shows the temporal profile of soil moisture (five satellite products and ground truth), expressed as (a) volumetric and (b) normalised data, for the three different locations (ZAK, EKI, AGT). Quantitative comparisons are provided in Fig. 11 which represents scatterplots between soil moisture products and ground stations. Table 4 gives statistics (correlation, RMSE, bias) of this evaluation at several temporal scales, averaged on the three ground stations. 
Table 4. Average of statistical results obtained product and stations for two years period, monsoon periods, and dry seasons. RMSE and bias are in $\% \mathrm{~m}^{3} / \mathrm{m}^{3}$, $\mathrm{N}$ indicates the number of data.

\begin{tabular}{|c|c|c|c|c|c|c|c|c|c|c|c|c|}
\hline \multirow[b]{2}{*}{ PRODUCT } & \multicolumn{4}{|c|}{ Two year } & \multicolumn{4}{|c|}{ Monsoon seasons } & \multicolumn{4}{|c|}{ Dry seasons } \\
\hline & Corr & RMSE & Bias & $\mathrm{N}$ & Corr & RMSE & Bias & $\mathrm{N}$ & Corr & RMSE & Bias & $\mathrm{N}$ \\
\hline AMSR-E/NSIDC & 0.59 & 5.91 & 5.31 & 334 & 0.42 & 4.48 & 3.25 & 102 & 0.34 & 6.47 & 6.33 & 23 \\
\hline AMSR-E/VUA & 0.82 & 3.33 & 1.27 & 335 & 0.60 & 5.46 & 3.65 & 102 & 0.58 & 1.75 & 0.31 & 23 \\
\hline ERS/CETP & 0.63 & 5.23 & 4.14 & 83 & 0.52 & 5.70 & 3.91 & 27 & -0.02 & 4.88 & 4.37 & 56 \\
\hline ERS/TUW & 0.52 & 5.41 & 4.15 & 151 & 0.31 & 6.30 & 4.10 & 49 & 0.04 & 4.97 & 4.41 & 102 \\
\hline TMI/VUA & 0.72 & 3.94 & 2.82 & 274 & 0.52 & 5.02 & 3.18 & 80 & 0.48 & 3.38 & 2.74 & 194 \\
\hline
\end{tabular}

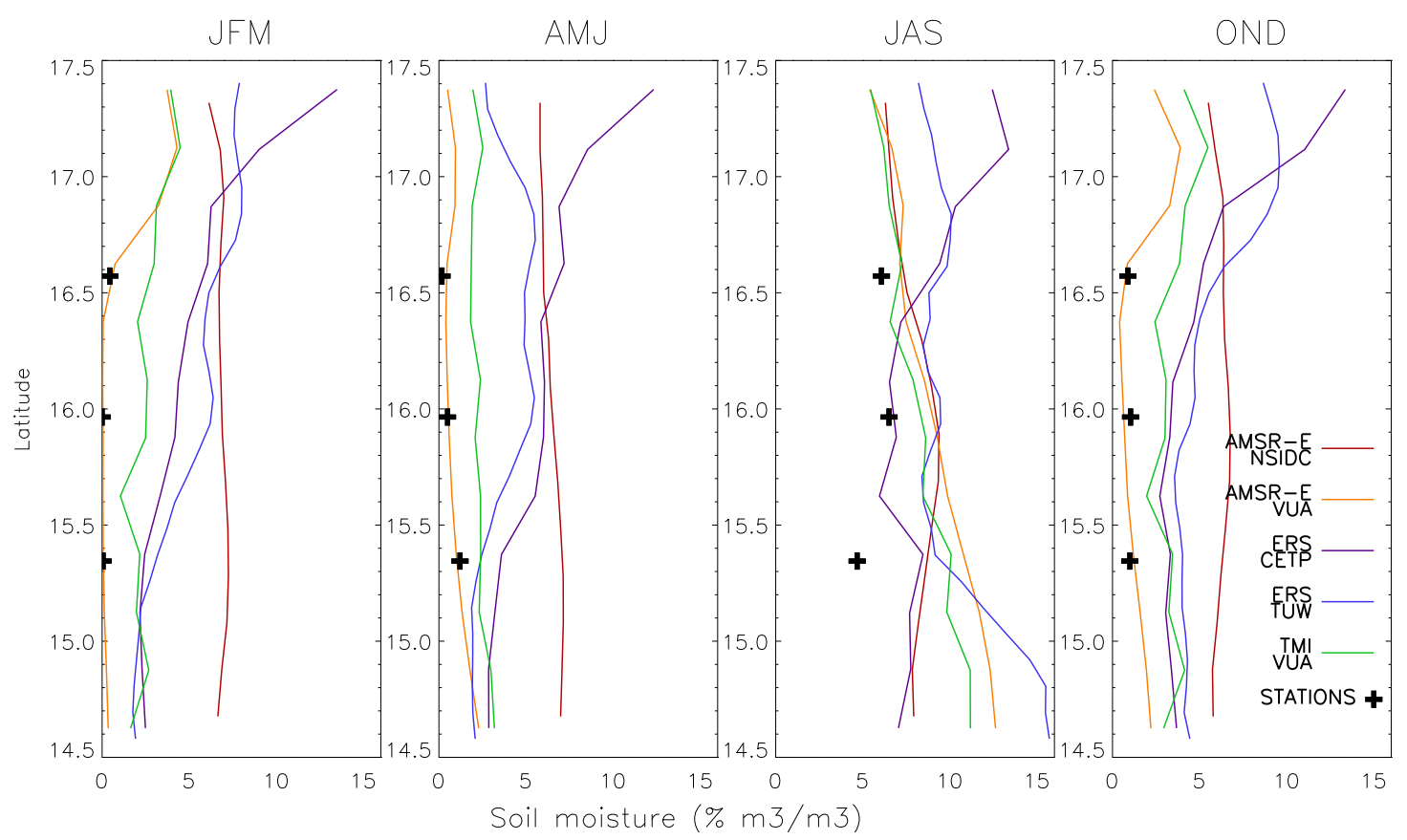

Fig. 9. Latitudinal distribution of soil moisture for January-February-March (JFM), April-May-June (AMJ), July-August-September (JAS), October-November-December (OND), based on 2005-2006 data. The five soil moisture products are represented by color lines (ASMRE/NSIDC, AMSR-E/VUA, ERS/CETP, ERS/TUW, TMI/VUA). Ground stations soil moisture values are indicated by black crosses.

Figure 10 shows that all products and ground stations indicate soil moisture increase during the monsoon seasons in summer 2005 and in summer 2006. However, the scatter between soil moisture products and ground stations is important (Fig. 11). The five satellite soil moisture products overestimate soil moisture during dry seasons as clearly shown in Fig. 10a and in Fig. 11 for low soil moisture values. This is particularly the case for the AMSR-E/NSIDC product which therefore considerably underestimates the seasonal amplitude of soil moisture. However normalised values of AMSR-E/NSIDC product indicate that soil moisture dynamics and variability is qualitatively well captured for this product as well as for the other products (Fig. 10).

Table 4 shows that the AMSR-E/VUA soil moisture product is in best agreement with ground measurements at any temporal scale, with highest correlation values during all periods and lowest RMSE for the two years $\left(3.33 \% \mathrm{~m}^{3} / \mathrm{m}^{3}\right)$ and for the dry seasons periods $\left(1.75 \% \mathrm{~m}^{3} / \mathrm{m}^{3}\right)$. TMI/VUA with correlation values of $0.72,0.52$, and 0.48 is close to AMSRE/VUA in terms of performances (lower less than about 0.1). This product also provides interesting RMSE values during the two years and dry seasons periods (less than $4 \% \mathrm{~m}^{3} / \mathrm{m}^{3}$ ). ERS/CETP product well reproduces soil moisture variations, with correlation values of 0.63 and 0.52 for 2005-2006 and for monsoon periods. It has poor correlation with ground data for dry season periods $(-0.02)$, for which soil moisture variability is very low. In terms of accuracy of soil moisture values, the RMSE values (range of 4.48 to 6.30 ) show than none of the products reach the target accuracy of $4 \% \mathrm{~m}^{3} / \mathrm{m}^{3}$ during the monsoon period. The large differences of performances between the products result from differences between measurements approaches and frequencies, as well as differences in inversion algorithm methods, as described in Sect. 2.2. 

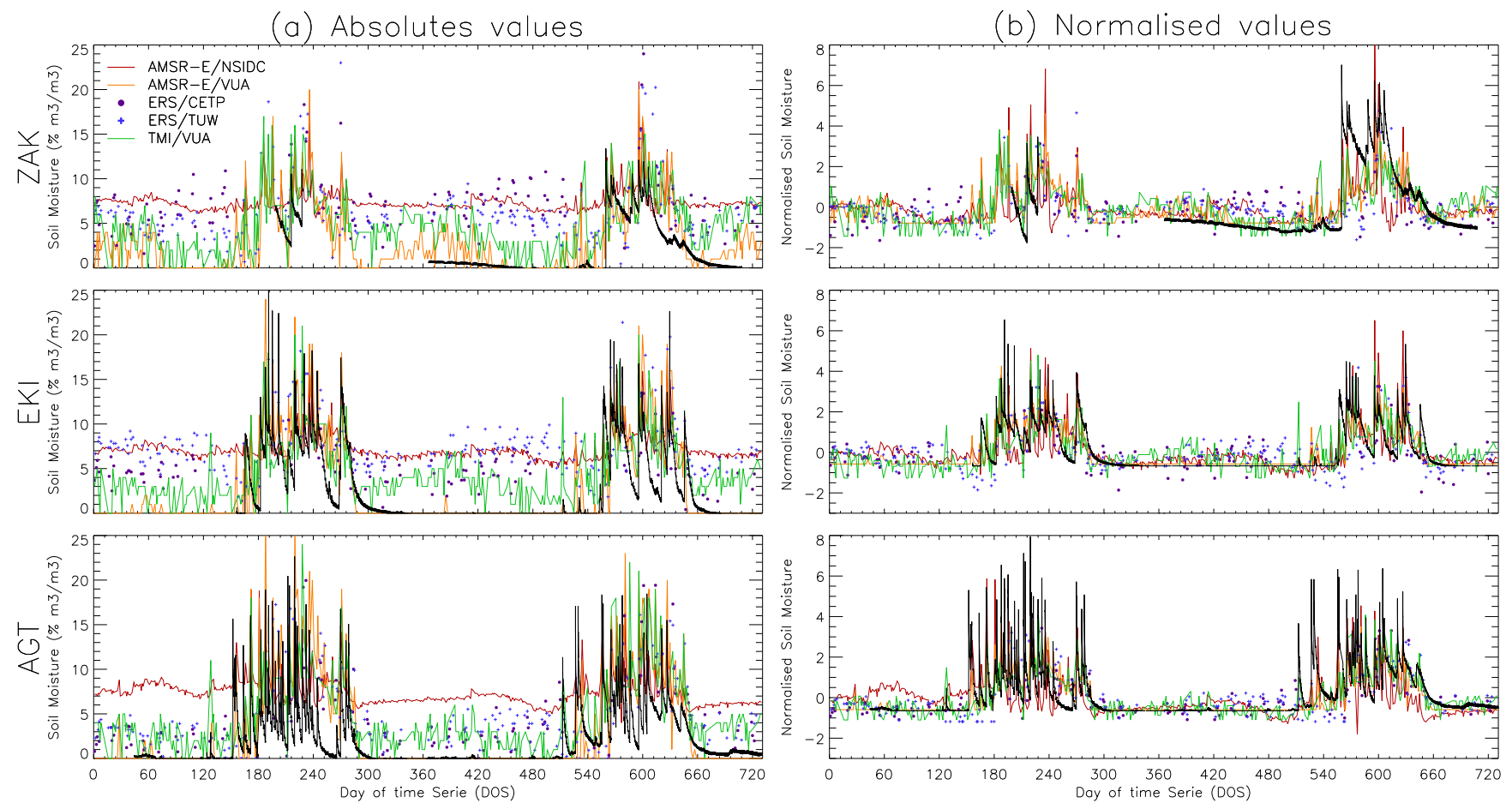

Fig. 10. Soil moisture values from all soil moisture products over the three ground stations for 2005 and 2006 . The ground measurements are represented by the black line while soil moisture products are shown by color lines (ASMR-E/NSIDC, AMSR-E/VUA, TMI/VUA) and color dots (ERS/CETP, ERS/TUW).

Figure 10 shows that most soil moisture products are affected by relatively large noise during dry periods, while ground data indicate steady soil moisture values close to $0 \% \mathrm{~m}^{3} / \mathrm{m}^{3}$. However, soil moisture remote sensing is of highest interest during the monsoon seasons during which atmospheric feedbacks are very strong. Most products perform satisfactorily during the monsoon seasons with correlation ranging from 0.31 for ERS/TUW to 0.6 for AMSR-E/VUA.

\section{Conclusions}

This paper provides an inter-comparison and evaluation of five products derived from three different satellite sensors (active and passive microwaves): four surface soil moisture and one soil moisture index which is converted to volumetric values to be comparable to the other products. The study has been performed over a Sahelian area located in the Gourma-Mali region during two consecutive years (2005-2006). Products are inter-compared and evaluated using local ground station measurements from three different ground sites.

A comparison of the products by pairs was performed according to similarities in terms of sensor or retrieval approaches. The resulting products derived from AMSR-E data but different retrieval approaches (AMSR-E/NSIDC and AMSR-E/VUA), are shown to be very different in terms of soil moisture distribution. In contrast, ERS products from TUW and CETP, both obtained from ERS C-band backscattering coefficients and calibrated using ground data, provide similar soil moisture values. The AMSR-E/VUA and TMI/VUA products obtained by VUA using the LPRM retrieval model at C-band and $\mathrm{X}$-band are very similar in terms of value and spatial and temporal distribution of soil moisture. This results show the importance of an efficient retrieval algorithm which can provide suitable soil moisture values even if non-optimal remote sensing frequencies is used.

The five products capture the seasonal soil moisture variations. However, the range of soil moisture variations is very different between the products. Verification against ground measurements shows that AMSR-E/NSIDC soil moisture data strongly under-estimate the range of soil moisture variations and do not capture low soil moisture values during dry season or between two precipitation events during the monsoon season. The other products are in better agreement with the ground data although they also tend to overestimate low soil moisture values in dry conditions. ERS/CETP and ERS/TUW present acceptable performances but they both overestimate soil moisture in the northern part of the area. AMSR-E/VUA and TMI/VUA products have the best 

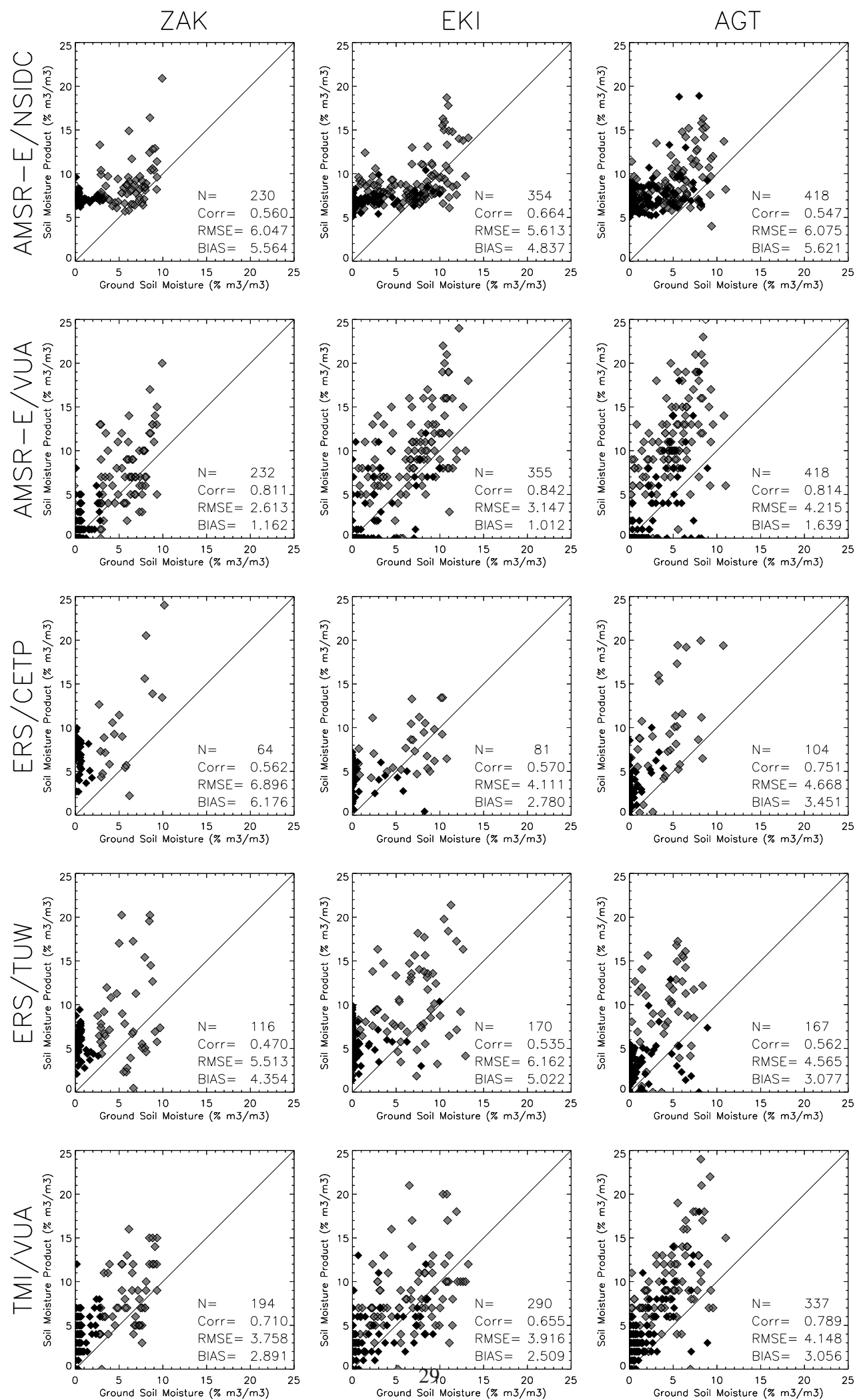

Fig. 11. Soil moisture from products versus from ground measurements. Black points correspond to dry seasons (October to June) and grey points to monsoon seasons (July-August-September). Statistical results shown are calculated during two years period. 
performances in terms of soil moisture retrieval when compared to ground station measurements, with correlation values above 0.81 and RMSE less than $4.2 \% \mathrm{~m}^{3} / \mathrm{m}^{3}$ for all three sites considered.

This first large scale inter-comparison of active and passive microwave soil moisture products over Sahel shows that both active and passive low frequency remote sensing approaches are sensitive to surface soil moisture variations. The soil moisture product (ERS/CETP) and the soil moisture index (ERS/TUW) based applied on both ERS-1 and ERS-2 data enables to have a long and continuous time record (since 1992). However, best performances over the study area were clearly obtained using the VU University Amsterdam product, which is based on AMSR-E C-band passive microwave measurements. This study also demonstrates that, all things considered, the retrieval accuracy is as much linked to the sensor (within a category) than to the algorithm used. In passive microwaves the VUA algorithm applied to AMSR-E (C band) and TMI ( $\mathrm{X}$ band) behaves similarly but very differently than that of NSIDC applied to AMSR-E (X band).

These results will be used in the framework of the validation of the SMOS L-band instrument which will provide soil moisture values from January 2010. Knowledge of accuracy of current soil moisture products is a highly valuable information used as a reference to compare with SMOS soil moisture products.

Acknowledgements. The ground validation data set was obtained in the framework of the AMMA (African Monsoon Multidisciplinary Analysis) Program. Based on a French initiative, AMMA was built by an international scientific group and is currently funded by a large number of agencies, especially from France, UK, US and Africa. It has been the beneficiary of a major financial contribution from the European Community Sixth Framework Research Program. Detailed information on scientific coordination and funding is available on the AMMA International web site http://www.amma-international.org.

Edited by: N. Verhoest

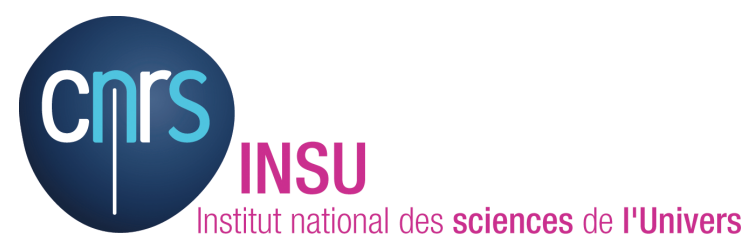

The publication of this article is financed by CNRS-INSU.

\section{References}

Baup, F., Mougin, E., de Rosnay, P., Timouk, F., and Chênerie, I.: Surface soil moisture estimation over the AMMA Sahelian site in Mali using ENVISAT/ASAR data, Remote Sens. Environ., 109(4), 473-481, doi:10.1016/j.rse.2007.01.015, 2007.

Boone, A., de Rosnay, P., Balsamo, G., Beljaars, A., Chopin, F., Decharme, B., Delire, C., Ducharne, A., Gascoin, S., Guichard, F., Gusev, Y., Harris, P., Jarlan, L., Kergoat, L., Mougin, E., Nasonova, O., Norgaard, A., Orgeval, T., Ottlé, C., PoccardLeclercq, I., Polcher, J., Sandholt, I., Saux-Picart, S., Taylor, C., and Xue, Y.: The AMMA Land Surface Model Intercomparison Project (ALMIP), Bull. Am. Meteorol. Soc., 90(12), 1865-1880, doi:10.1175/2009BAMS2786.1, 2009

de Rosnay, P., Drusch, M., Boone, A., Balsamo, G., Decharme, B., Harris, P., Kerr, Y., Pellarin, T., Polcher, J., and Wigneron, J.-P.: Microwave Land Surface modelling evaluation against AMSR-E data over West Africa. The AMMA Land Surface Model Intercomparison Experiment coupled to the Community Microwave Emission Model (ALMIP-MEM), J. Geophys. Res, 114, doi:10.1029/2008JD010724, 2009a.

de Rosnay, P., Gruhier, C., Timouk, F., Baup, F., Mougin, E., Hiernaux, P., Kergoat, L., and LeDantec, V.: Multi-scale soil moisture measurements at the Gourma meso-scale site in Mali, J. Hydrol., 375, 241-252, doi:10.1016/j.jhydrol.2009.01.015, 2009b.

Dirmeyer, P. A., Guo, Z., and Gao, X.: Comparison, Validation, and Transferability of Eight Multiyear Global Soil Wetness Products, J. Hydrometeorol., 5(6), 1011-1033, doi:10.1175/JHM-388.1, 2004.

Dirmeyer, P. A., Gao, X., Guo, Z., Oki, T., and Hanasaki, N.: The Second Global Soil Wetness Project (GSWP-2): Multi-model analysis and implications for our perception of the land surface, Bull. Americ. Met. Soc., 87(10), 1381-1397, doi:10.1175/ BAMS-87-10-1381, 2006.

Draper, C., Walker, J., Steinle, P., de Jeu, R., and Holmes, T.: An evaluation of AMSR-E derived soil moisture over Australia, Remote Sens. Environ., 113(4), 703-710, doi:10.1016/j.rse.2008. 11.011, 2009.

European Space Agency, E.: Satellite Data in Hydrology. Experience with ERS, ESA Publications Division, SP-1207, 1997.

Frappart, F., Hiernaux, P., Guichard, F., Mougin, E., Kergoat, L., Arjounin, M., Lavenu, F., Koité, M., Paturel, J.-E., and Lebel, T.: Rainfall regime across the Sahel band in the Gourma region, Mali, J. Hydrol., 375, 128-142, doi:10.1016/j.jhydrol.2009.03. 007, 2009.

Gruhier, C., de Rosnay, P., Kerr, Y. H., Mougin, E., Ceschia, E., Calvet, J.-C., and Richaume, P.: Evaluation of AMSR-E soil moisture product based on ground measurements over temperate and semi-arid regions, Geophys. Res. Lett., 35, L10405, doi:10.1029/2008GL03333, 2008.

Jones, A., Vukićević, T., and Vonder Haar, T.: A microwave satellite observational operator for variational data assimilation of soil moisture, J. Hydrometeorol., 5(1), 213-229, doi:10.1175/ 1525-7541(2004)005<0213:AMSOOF〉 2.0.CO;2, 2004.

Kerr, Y. H.: Soil Moisture from space: Where we are?, Hydrogeol. J., 15, 117-120, doi:10.1007/s10040-006-0095-3, 2007. 
Kerr, Y. H., Waldteufel, P., Wigneron, J.-P., Martinuzzi, J.M., Font, J., and Berger, M.: Soil moisture retrieval from Space: The soil moisture and ocean salinity (SMOS) mission, IEEE Trans. Geosc. Remote, 39(8), 1729-1735, doi:10.1109/36. 942551, 2001.

Koster, R. D., Dirmeyer, P., Guo, Z., Bonan, G., Cox, P., Gordon, C., Kanae, S., Kowalczyk, E., Lawrence, D., Liu, P., Lu, C., Malyshev, S., McAvaney, B., Mitchell, K., Mocko, D., Oki, T., Oleson, K., Pitman, A., Sud, Y., Taylor, C., Verseghy, D., Vasic, R., Xue, Y., and Yamada, T.: Regions of Strong Coupling Between Soil Moisture and Precipitation, Sciences, 305(5687), 1138-1140, doi:10.1126/science.1100217, 2004.

Lebel, T., Cappelaere, B., Galle, S., Hanan, N., Kergoat, L., Levis, S., Vieux, B., Descroix, L., Gosset, M., Mougin, M., Peugeot, C., and Seguis, L.: AMMA-CATCH studies in the Sahelian region of West-Africa: an overview., J. Hydrol., 375, 3-13, doi:10.1016/j. jhydrol.2009.03.020, 2009.

Magagi, R. and Kerr, Y.: Retrieval of soil moisture and vegetation characteristics by use of ERS-1 wind scatterometer over arid and semi-arid areas, J. Hydrol., 188-189, 361-384, doi: 10.1016/S0022-1694(96)03166-6, 1997.

Merlin, O., Walker, J. P., Chehbouni, A., and Kerr, Y. H.: Towards deterministic downscaling of SMOS soil moisture using MODIS derived soil evaporative efficiency, Remote Sens. Environ., 112(10), 3935-3946, doi:10.1016/j.rse.2008.06.012, 2008.

Mougin, E., Hiernaux, P., Kergoat, L., Grippa, M., de Rosnay, P., Timouk, F., Le Dantec, V.and Demarez, V., Arjounin, M., Lavenu, F., Soumaguel, N., Ceschia, E., Mougenot, B., Baup, F., Frappart, F., Frison, P., Gardelle, J., Gruhier, C., Jarlan, L., Mangiarotti, S., Sanou, B., Tracol, Y., Guichard, F., Trichon, V., Diarra, L., Soumaré, A., Koité, M., Dembélé, F., Lloyd, C., Hanan, N., Damesin, C., Delon, C., Serça, D., Galy-Lacaux, C., Seghieri, J., Becerra, S., Dia, H., Gangneron, F., and Mazzega, P.: The AMMA-CATCH Gourma observatory site in Mali: Relating climatic variations to changes in vegetation, surface hydrology, fluxes and natural resources, J. Hydrol., 375, 14-33, doi:10.1016/j.jhydrol.2009.06.045, 2009.

Njoku, E.: Updated daily. AMSR-E/AQUA daily L3 surface soil moisture, interpretive parms, \& QC EASE-Grids, Boulder, CO, USA: National Snow and Ice Data Center, Digital Media, 2004.

Njoku, E. and Entekhabi, D.: Passive microwave remote sensing of soil moisture, J. Hydrol., 184, 101-129, doi:10.1016/ 0022-1694(95)02970-2, 1996.

Njoku, E., Jackson, T., Lakshmi, V., Chan, T., and Nghiem, S.: Soil moisture retrieval from AMSR-E, IEEE Geosc. Remote Sens. Lett., 41(2), 215-229, doi:10.1109/TGRS.2002.808243, 2003.

Owe., M., de Jeu, R., and Holmes, T.: Multi-sensor historical climatology of satellite derived global land surface soil moisture, J. Geophys. Res., 113, F01002, doi:10.1029/2007JF000769, 2008.
Pellarin, T., Calvet, J.-C., and Wagner, W.: Evaluation of ERS scatterometer soil moisture products over a half-degree region in southwestern France., Geophy. Res. Lett., 33, L17401, doi:10.1029/2006GL027231, 2006.

Redelsperger, J.-L., Thorncroft, C., Diedhiou, A., Lebel, T., Parker, D., and Polcher, J.: African Monsoon, Multidisciplinary Analysis (AMMA): An International Research Project and Field Campaign, Bull. Amer. Meteorol. Soc, 87(12), 1739-1746, doi: 10.1175/BAMS-87-12-1739, 2006.

Rüdiger, C., Calvet, J.-C., Gruhier, C., Holmes, T. R. H., de Jeu, R. A. M., and Wagner, W.: An Intercomparison of ERS-Scat and AMSR-E Soil Moisture Observations with Model Simulations over France, American Meteorological Society, 10, 431447, doi:10.1175/2008JHM997.1, 2009.

Samain, O., Kergoat, L., Hiernaux, P., Guichard, F., Mougin, E., Timouk, F., and Lavenu, F.: Analysis of the in-situ and MODIS albedovariability at multiple time scale in the Sahel, J. Geophys. Res, 113, D14119, doi:10.1029/2007JD009174, 2008.

Taylor, C.: Intraseasonal land-atmosphere coupling in the West African Monsoon, J. Climate, 21(24), 6636-6648, doi:10.1175/ 2008JCLI2475.1, 2008.

Taylor, C., Kergoat, L., and de Rosnay, P.: The diurnal cycle and African easterly waves: A land surface perspective, Clivar Exchanges News Letter, AMMA special issue, 12(2)-No41, 20-21, 2007.

Vachaud, G., Passerat De Silans, A., Balabanis, P., and Vauclin, M.: Temporal Stability of Spatially Measured Soil Water Probability Density Function, Soil Sci. Soc. Am. J., 49, 822-828, 1985.

Wagner, W., Lemoine, G., and Rott, H.: A Method for Estimating Soil Moisture from ERS Scatterometer and Soil Data, Remote Sens. Environ., 70(2), 191-207, doi:10.1016/S0034-4257(99) 00036-X, 1999.

Wagner, W., Scipal, K., Pathe, C., Gerten, D., Lucht, W., and Rudolf, B.: Evaluation of the agreement between the first global remotely sensed soil moisture data with model and precipitation data, J. Geoph. Res., 108(D19), 4611, doi:10.1029/ 2003JD003663, 2003.

Wagner, W., Naeimi, V., Scipal, K., de Jeu, R., and MartínezFernández, J.: Soil moisture from operational meteorological satellites, Hydrogeol. J., 15(1), 121-131, doi:10.1007/ s10040-006-0104-6, 2007.

Zribi, M., André, C., and Decharme, B.: A method for soil moisture estimation in Western Africa based on ERS Scatterometer, IEEE T. Geosci. Remote, 46(2), 438-448, doi:10.1109/TGRS. 2007.904582, 2009. 